\title{
STUDIES ON HEPATOPROTECTIVE AND ANTI-INFLAMMATORY ACTIVITY OF COIX LACRYMA-JOBI (LINN)
}

\section{GEETHA $S^{1}$, JANNATHUL FIRDOUS ${ }^{2 *}$, KARPAGAM T ${ }^{3}$, VARALAKSHMI ${ }^{3}{ }^{3}$, SHANMUGA PRIYA ${ }^{3}$, SUGUNABAI $\mathbf{J}^{4}$, GOMATHI $S^{3}$}

${ }^{1}$ Department of Biochemistry, School of Life Sciences, Vels Institute of Science, Technology and Advanced Studies, Chennai, Tamil Nadu, India. ${ }^{2}$ Department of Preclinical, Faculty of Medicine, Universiti Kuala Lumpur Royal College of Medicine Perak, No.3, Jalan Greentown, 30450, Ipoh, Perak, Malaysia. ${ }^{3}$ Department of Biochemistry, Shrimati Indira Gandhi College, Tiruchirappalli, Tamil Nadu, India. ${ }^{4}$ Department of Biochemistry, Seethalakshmi Ramaswami College, Tiruchirappalli, Tamil Nadu, India. Email: jannathul.firdous@unikl.edu.my

Received: 28 March 2018, Revised and Accepted: 12 July 2018

ABSTRACT

Objective: In the present study, evaluation of hepatoprotective activity of Coix lacryma-jobi by $\mathrm{CCl}_{4}$-induced hepatotoxicity test, and evaluation of antiinflammatory activity of by egg albumin-induced paw edema, and complete Freund's adjuvant-induced arthritis model were done.

Methods: Plant extract was prepared by mixing ethanol with powdered plant seeds and experiment was done as per the procedures of abovementioned three models.

Results: C. lacryma-jobi test extracts out of two doses, $400 \mathrm{mg} / \mathrm{kg}$ exhibited a significant reduction in serum cholesterol level as $33 \mathrm{mg} / \mathrm{dl}$ when compared to control groups. C. lacryma-jobi seed extract has restored various serological alterations following $\mathrm{CCl}_{4}$-induced hepatotoxicity and was capable of reversing the toxic effects of $\mathrm{CCl}_{4}$ on liver cells. Considerable reduction in the paw volume of exudates observed with $C$. lacryma-jobi extract, indicating significant anti-inflammatory activity.

Conclusion: Therefore, this study shows that C. lacryma-jobs seed extract have anti-inflammatory activity in the models studied.

Keywords: Anti-inflammation, Coix lacryma-jobi, Hepatotoxicity, Rheumatoid arthritis, and Edema.

(C) 2018 The Authors. Published by Innovare Academic Sciences Pvt Ltd. This is an open access article under the CC BY license (http://creativecommons. org/licenses/by/4. 0/) DOI: http://dx.doi.org/10.22159/ajpcr.2018.v11i11.26307

\section{INTRODUCTION}

Liver is the major organ to play various functions such as metabolism, secretion, storage, and even detoxification of drugs. Disorders in liver cause serious health problems that may be chronic or acute. Infections, toxic chemicals, autoimmune disorders, and more alcohol consumption are responsible for liver disorders [1]. Lipid peroxidation and oxidative damage make the liver worsen resulting in hepatitis which is caused by toxic chemicals and viruses. Chronic liver diseases, cirrhosis, and primary liver cancer, may even cause by viruses [2]. Through medication, the hepatoprotective activity can be improved by enhancing the antioxidant capacity. However, these synthetic drugs are insufficient in stimulating liver function. They also can cause side effects when taken in a longer duration [3].

Rheumatoid arthritis (RA) is a symmetric polyarticular disease that primarily affects small diarthrodial joints of the body. Symptoms range from mild annoyance to crippling disability. The clinical course ranges from mild, self-limiting arthritis to rapidly progressive multisystem inflammation with profound morbidity and mortality. Nonsteroidal anti-inflammatory drugs, disease-modifying anti-rheumatic drugs are used to treat RA. Various biological agents that target pro-inflammatory cytokines, cell surface receptors are also utilized in the treatment of RA [4]. As previously mentioned, therapeutic drugs are not promising for long-term effects as they cause adverse side effects.

In such a scenario, plant products are less toxic with minimal side effects. Traditional medicines are used to treat various infectious and hereditary diseases throughout the world by various communities. Knowledge of herbs to produce drugs is the significant measure to treat diseases. For the treatment of liver diseases, medicinal plants were used in ancient years thereby prevent any hepatic damage and helps in hepatic cell regeneration [5]. Coix lachrymajobi L. also called Adlay has been used long-term in China for treating inflammatory diseases, warts, neuralgia, and neoplastic diseases [6]. Various external or internal stimuli cause the activation and release of biogenetic amines and peptides like histamine to produce inflammation by increasing the permeability of capillaries. C. lachryma-jobi L. acts as anti-inflammatory agents. Presence of phytochemicals such as flavonoids in adlay is responsible for antiinflammatory effect [7]. They also protect the liver by activating various liver enzymes and stimulate hepatic cell regeneration. Adlay found to possess various pharmacological activities, which forms the basis of the present study. Therefore, this study was aimed at investigating the hepatoprotective effects of $C$. lachryma-jobi L. by $\mathrm{CCl}_{4}$-induced hepatotoxicity model and its anti-inflammatory activity by egg albumin-induced paw edema and complete Freund's adjuvantinduced arthritis model.

\section{MATERIALS AND METHODS}

\section{Preparation of plant extract}

Seeds were powdered (50 g) and were added to $250 \mathrm{ml}$ of $70 \%$ ethanol. The extract was double filtered, and the finally collected filtrate was stored in the refrigerator before use.

\section{Animals}

Albino rats between 200 and $250 \mathrm{~g}$ were purchased and were kept in polypropylene cages (three in each) under standard conditions (temperature $25-29^{\circ} \mathrm{C}, 12 \mathrm{~h}$ light $12 \mathrm{~h}$ darkness cycles, and $55-65 \%$ relative humidity). Animals were fed with pelleted standard rat diet and water. 
Table 1: Effect of Coixlacryma-jobi seed extracts on various biochemical parameters

\begin{tabular}{|c|c|c|c|c|}
\hline Group & Serum alkaline phosphatase & serum cholesterol & serum triglyceride & total protein \\
\hline Normal control & $46.71 \pm 1.09$ & $42.11 \pm 1.50$ & $112.68 \pm 1.65$ & $10.21 \pm 1.14$ \\
\hline Negative control & $85.01 \pm 0.45$ & $111.39 \pm 1.69$ & $82.03 \pm 1.88$ & $6.29 \pm 0.45$ \\
\hline Test 200 mg/kg & $32.64 \pm 1.33$ & $62.40 \pm 1.06$ & $91.06 \pm 1.94$ & $10.21 \pm 0.96$ \\
\hline Test $400 \mathrm{mg} / \mathrm{kg}$ & $41.25 \pm 1.45$ & $33.10 \pm 1.21$ & $108.40 \pm 1.45$ & $11.50 \pm 0.78$ \\
\hline Standard silymarin $100 \mathrm{mg} / \mathrm{kg}$ & $40.44 \pm 1.03$ & $32.86 \pm 1.59$ & $95.56 \pm 1.82$ & $9.15 \pm 0.97$ \\
\hline
\end{tabular}

Values are mean \pm SEM. SEM: Standard error of the mean

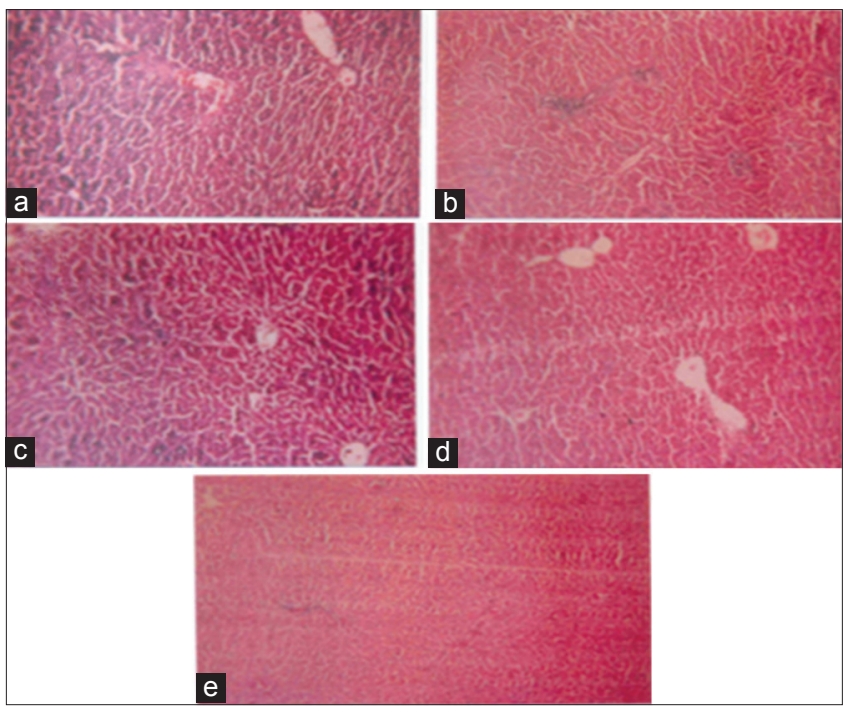

Fig. 1: Histopathology of liver tissues. (a) Normal Control showing cords of hepatocytes around the central vein and (b) negative control showing liver with focal hepatocyte damage and inflammatory collection. Portal infiltration is evident, (c) test $200 \mathrm{mg} / \mathrm{kg}$ treated showing minimal inflammatory collection and damaged hepatocytes, (d) test $400 \mathrm{mg} / \mathrm{kg}$ treated: Liver appearing normal no foci of damage or inflammatory collections, and (e) standard treated silymarin $100 \mathrm{ml} / \mathrm{kg}$ : Liver appearing to normal

\section{$\mathrm{CCl}_{4}$-induced hepatotoxicity mode}

This method was determined according to the previously explained procedure [8]. The animals were divided into 5 groups of 8 rats in each, where Group 1 (Normal control) - $1 \mathrm{ml} / \mathrm{kg}$ body w.t. of liquid paraffin, Group 2 (Negative control) - $1 \mathrm{ml} / \mathrm{kg}$ body w.t. of $\mathrm{CCl}_{4}$ was given intraperitoneally, Group 3 (test Group-1) - $200 \mathrm{mg} / \mathrm{kg}$ of C. lacryma-jobi was given orally (P.O.), Group 4 (test Group-2) - $400 \mathrm{mg} / \mathrm{kg}$ of C. lacrymajobi (P.O.), and Group 5 (standard) - $100 \mathrm{mg} / \mathrm{kg}$ of Silymarin (P.O.). Serum alkaline phosphatase, serum cholesterol, serum triglycerides, and total proteins were determined.

\section{Egg albumin-induced paw edema model}

This method was followed by the guidelines of Shorinwa et al. [9]. Groups were Group 1 (Normal control) - $1 \mathrm{ml} / \mathrm{kg}$ of 2\% Tween 80 (P.O.), Group 2 (Standard) - $100 \mathrm{mg} / \mathrm{kg}$ of acetylsalicylic acid by (P.O.), Group 3 (test Group-1) - $200 \mathrm{mg} / \mathrm{kg}$ of C. lacryma-jobi (P.O.), and Group 4 (test Group-2) - $400 \mathrm{mg} / \mathrm{kg}$ of C. lacryma-jobi (P.O.). Edema induced with $0.1 \mathrm{ml}$ of fresh undiluted egg albumin injected into subplantar region of the hind paw of rats. The volume of mercury displaced by the treated paw was measured in plethysmometer before and at different time intervals.

Complete Freund's adjuvant-induced arthritis model

For the anti-inflammatory effect of drugs, this model was well documented [10]. Animals rendered arthritic by single subcutaneous injection of $0.5 \mathrm{ml}$ of Freund's complete adjuvant (FCA). Groups were Group 1 (Normal control) - $1 \mathrm{ml} / \mathrm{kg}$ of $2 \%$ Tween 80 (P.O.), Group 2 (Standard) - $20 \mathrm{mg} / \mathrm{kg}$ of indomethacin (P.O.), Group 3 (test Group-1)
- $200 \mathrm{mg} / \mathrm{kg}$ of C. lacryma-jobi (P.O.), and Group 4 (test Group-2) - $400 \mathrm{mg} / \mathrm{kg}$ of C. lacryma-jobi (P.O.). The volume of mercury displaced by the treated paw was measured in plethysmometer before and at different day intervals.

\section{RESULTS AND DISCUSSION}

C. lacryma-jobi reported to possess various pharmacological activities and so selected for the present study. The ALP activity was measured with a color reaction assay [11]. Effect of C. lacryma-jobi on various parameters such as alkaline phosphatase, total proteins, serum cholesterol, and serum triglycerides was assessed as shown in Table 1.

Liver damage was assessed by increased levels of serum ALP levels [12]. Serum ALP level in the rat (Group 4) when given C. lacryma-jobi seed extract, showed slightly high value than Group 3. It was well observed that the ALP levels decreased after the treatment in all test and standard rat groups. The ALT level, however, was noted to increase in the negative control rat group (Group 2). The results showed low ALP levels in test Group 3 and test Group 4 confirming the liver cell regeneration. The results were in line with the previous research done by Chen et al. [13]. Serum cholesterol was comparatively lower in test Groups (3 and 4). Results suggested that the extract reduced the synthesis of cholesterol. However, serum triglyceride levels were shown to increase in all groups when compared to the negative group. Total protein levels showed no significant changes among groups. The results were inconsistent with the reports by Feng et al. [12]

Findings of histopathological changes in the liver due to treatment with C. lacryma-jobi seed extract were shown in Fig. 1.

Liver from control groups showed normal hepatocyte structure. Histopathological lesions and hepatocellular damage occurred on the administration of $\mathrm{CCl}_{4}$. As shown in Fig. 1, negative control showed increased portal inflammation with venous congestion. Test groups showed minimal inflammation as compared to standard. Results indicated that treatment with $C$. lacryma-jobi seed extract decreases the signs of $\mathrm{CCl}_{4}$-induced toxicity similar to silymarin. The results are in line with previous findings by Kamisan et al. [15]. $\mathrm{CCl}_{4}$ rat model has been used to investigate liver injuries and to evaluate the preventive action of liver when treated. In general, free radicals formed are metabolized in the liver to produce lethal trichloromethyl free radicals $\left(\mathrm{CCl}_{3}\right)$ which can be converted to trichloromethyl peroxy radical $\left(\mathrm{CCl}_{3} \mathrm{OO}\right)$ through the cytochrome P450 oxygenase enzyme. This results in oxidative stress and cause autoxidation of lipids leading to liver diseases. To counteract oxidative stress, antioxidants are involved to neutralize excess free radicals [15]. Such antioxidative property is known to exist in C. lacryma-jobi seed extract [6]

Changes in paw volume of rats at different time intervals and different day intervals following the treatment with $C$. lacryma-jobi were analyzed, and the results were observed. Egg albumin-induced paw edema in rats is an acute inflammatory model, where infiltrations of exudates accumulate in response to fresh egg albumin injection. C. lacryma-jobi seed extract significantly reduced the inflammation induced by egg albumin as compared to standard. Fig. 2. shows the effect of $C$. lacryma-jobi seed extract on test groups at a different time.

Animals fed with C. lacryma-jobi seed extracts for 12 days and then given egg albumin were shown to increase in percentage inhibition of 


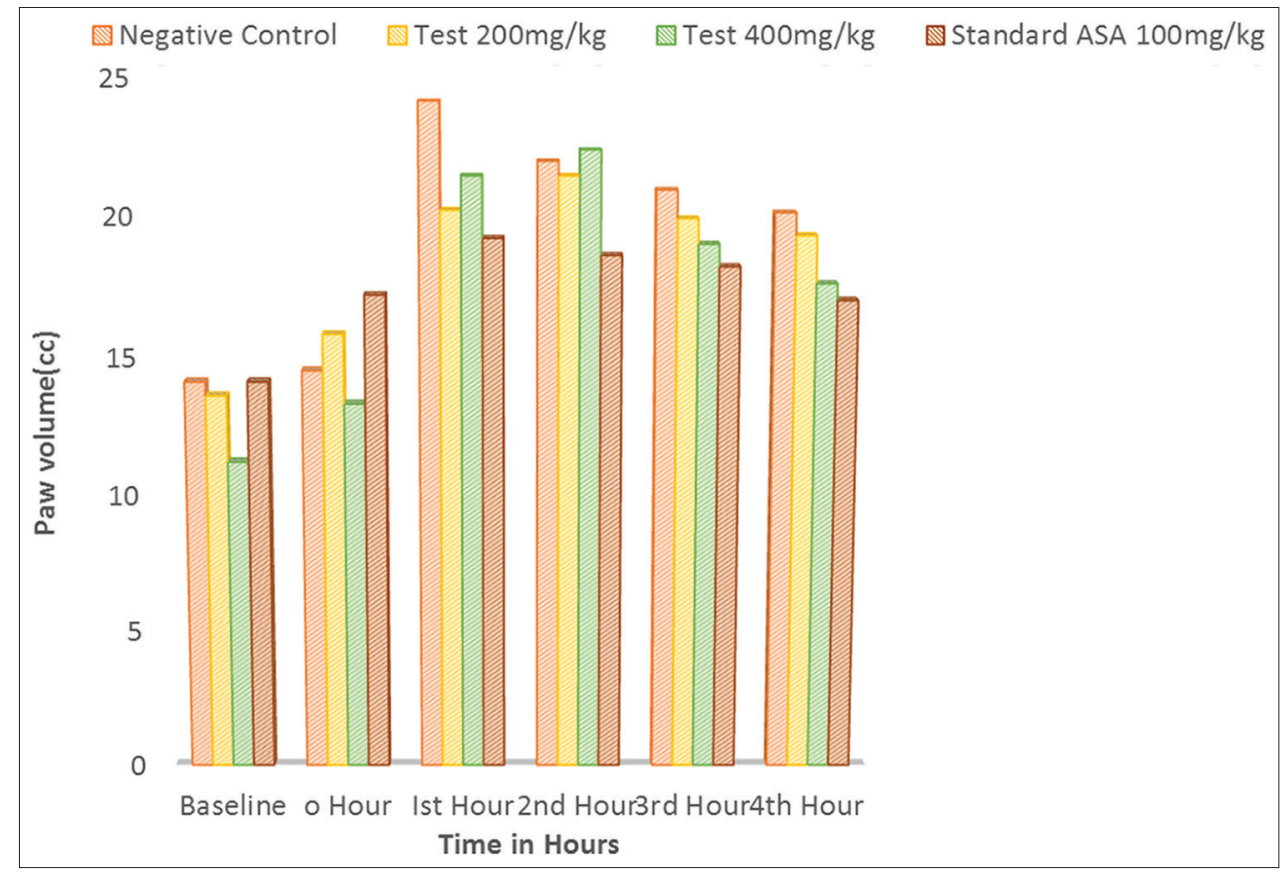

Fig. 2: Effects of Coix lacryma-jobi seed extract on paw volume at different time intervals

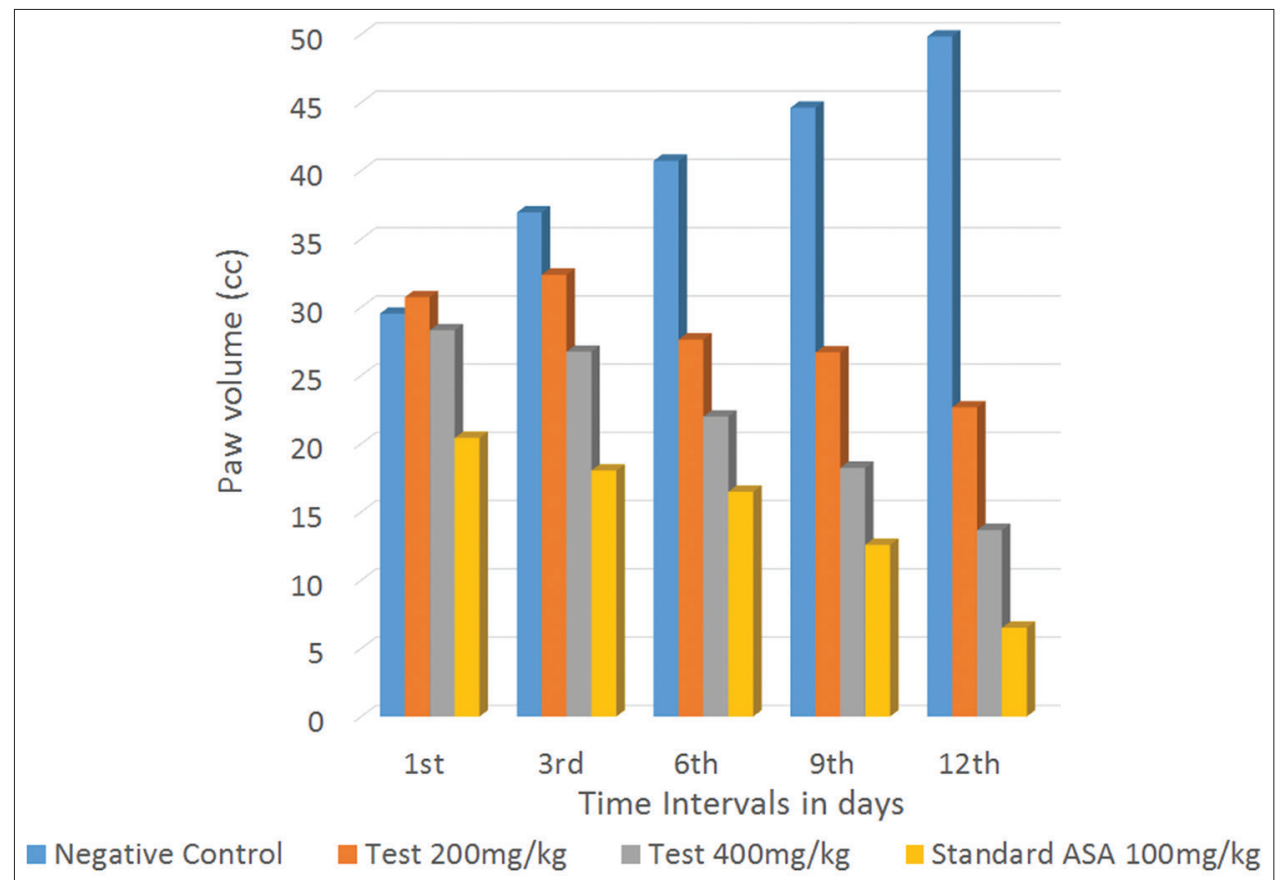

Fig. 3: Effects of Coix lacryma-jobi seed extract on paw volume at different day intervals

edema. Edema reduction occurred at different day intervals as shown in Fig. 3.

Injection of complete Freund's adjuvant induced the chronic inflammation as indicated by progressive increase in paw volume of injected paw. On a daily basis, the degree of arthritis was evaluated and assessed by visual observation. Plethysmometer was used to measure paw volume. Test groups, when treated with C. lacryma-jobi seed extract, showed significantly lowered paw volume from the $1^{\text {st }}$ day to until the end of treatment as compared to arthritis control group.

C. lacryma-jobi test extracts out of two doses 200 and $400 \mathrm{mg} / \mathrm{kg}$ exhibited anti-inflammatory activity on dose-dependent manner. They showed increased anti-inflammatory action by suppressing the egg albumin-induced rat paw edema and Freund's adjuvant-induced rat paw edema. Edema occurs due to release of histamine, serotonin, and bradykinin at the site of a local inflammatory insult which causes increased vascular permeability and blood flow [16]. Therefore, $C$. lacryma-jobi test extract may inhibit the release of such mediators at the local inflammatory site. Results indicated that when taken the test extract daily can protect the body against inflammation and also used to treat an inflammatory condition. Results are in accordance with report by Mbiantcha et al. [17].

\section{CONCLUSION}

C. lacryma-jobi has a definite hepatoprotective activity and may be used in the treatment of liver disorders such as liver dysfunction, 
hepatomegaly, jaundice, viral hepatitis, and various alcoholic liver disorders. C. lacryma-jobi possessed significant anti-inflammatory activity and may be used as an anti-inflammatory agent in the treatment of various infectious diseases. Further studies are required for isolation of the compounds and pharmacological investigations responsible for the above activity and its mechanism of action.

\section{AUTHORS' CONTRIBUTIONS}

All authors were equally involved in the manuscript's framework preparation and gathering all the necessary information.

\section{CONFLICTS OF INTEREST}

The authors have none to declare.

\section{REFERENCES}

1. Asadi-Samani M, Kafash-Farkhad N, Azimi N, Fasihi A, Alinia-Ahandani E, Rafieian-Kopaei M. Medicinal plants with hepatoprotective activity in Iranian folk medicine. Asian Pac J Trop Biomed 2015;5:146-57.

2. Agyare C, Spiegler V, Sarkodie H, Asase A, Liebau E, Hensel A, et al. An ethnopharmacological survey and in vitro confirmation of the ethnopharmacological use of medicinal plants as anthelmintic remedies in the Ashanti region, in the central part of Ghana. J Ethnopharmacol 2014;158 Pt A:255-63.

3. Chattopadhyay RR. Possible mechanism of hepatoprotective activity of Azadirachta indica leaf extract: Part II. J Ethnopharmacol 2003;89:217-9

4. Smolen JS, Steiner G. Therapeutic strategies for rheumatoid arthritis. Nat Rev Drug Discov 2003;2:473-88

5. Levy C, Seeff LD, Lindor KD. Use of herbal supplements for chronic liver disease. Clin Gastroenterol Hepatol 2004;2:947-56.

6. Kuo CC, Chen HH, Chiang W. Adlay (yì yı̆; "soft-shelled job's tears"; The seeds of Coix lachryma-jobi L. Var. Ma-yuen stapf) is a potential cancer chemopreventive agent toward multistage carcinogenesis processes. J Tradit Complement Med 2012;2:267-75.
7. Wang L, Sun J, Yi Q, Wang X, Ju X. Protective effect of polyphenols extract of adlay (Coix lachryma-jobi L. Var. Ma-yuen stapf) on hypercholesterolemia-induced oxidative stress in rats. Molecules 2012;17:8886-97.

8. Sumalatha S, Padma D, Pai KS, Kotian SR, Kumar N, Bhat KM. Hepatoprotective activity of aqueous extract of Caesalpenia bonduc against CCL4 induced chronic hepatotoxicity. Int J Pharm Pharm Sci 2016;8:207-11.

9. Shorinwa OA, Ubele C, Ukwueze SE. Evaluation of the analgesic and anti-inflammatory activities of ethanol extract of the root of Mimosa pigra linn (Fabaceae) in albino rats. Int J Pharm Pharm Sci 2015;7:376-9.

10. Ahmad AS, Chopde CT, Kashmiri ZN. Assessement of antiinflammatory and anti-arthritis activity of Jatropha gossypifolia in rats. Int J Pharm Pharm Sci 2015;7:258-60

11. Yang RS, Lu YH, Chiang W, Liu SH. Osteoporosis prevention by adlay (yì yǐ: The seeds of Coix lachryma-jobi L. Var. Ma-yuen stapf) in a mouse model. J Tradit Complement Med 2013;3:134-8.

12. Feng $\mathrm{Y}$, Siu KY, Ye X, Wang $\mathrm{N}$, Yuen MF, Leung $\mathrm{CH}$, et al. Hepatoprotective effects of berberine on carbon tetrachloride-induced acute hepatotoxicity in rats. Chin Med 2010;5:33.

13. Chen YH, Lan T, Li J, Qiu CH, Wu T, Gou HJ, et al. Gardenia jasminoides attenuates hepatocellular injury and fibrosis in bile ductligated rats and human hepatic stellate cells. World J Gastroenterol 2012:18:7158-65.

14. Kamisan FH, Yahya F, Ismail NA, Din SS, Mamat SS, Zabidi Z, et al. Hepatoprotective activity of methanol extract of Melastoma malabathricum leaf in rats. J Acupunct Meridian Stud 2013;6:52-5.

15. Mahmud Z, Bachar S, Qais N. Antioxidant and hepatoprotective activities of ethanolic extracts of leaves of Premna esculenta roxb. Against carbon tetrachloride-induced liver damage in rats. J Young Pharm 2012;4:228-34

16. Kang HS, Lee JY, Kim CJ. Anti-inflammatory activity of arctigenin from Forsythiae fructus. J Ethnopharmacol 2008;116:305-12

17. Mbiantcha M, Almas J, Shabana SU, Nida D, Aisha F. Anti-arthritic property of crude extracts of Piptadeniastrum africanum (Mimosaceae) in complete freund's adjuvant-induced arthritis in rats. BMC Complement Altern Med 2017;17:111. 